\title{
Insights into the nature of the active sites of tin-montmorillonite for the synthesis of polyoxymethylene dimethyl ethers (OME)
}

\author{
Christophe J. Baranowski, ${ }^{[a]}$ Ali M. Bahmanpour, ${ }^{[a]}$ Florent Héroguel, ${ }^{[a]}$ Jeremy S. Luterbacher, ${ }^{[a]}$ Oliver \\ Kröcher ${ }^{*}[a, b]$
}

\begin{abstract}
In this study, we report that intercalation of tin into montmorillonite clay (Sn-MMT) boosts catalytic activity for the synthesis of polyoxymethylene dimethyl ethers, a promising diesel fuel additive. This increase in activity is attributed to the formation of a hierarchical catalyst displaying high surface area with accessible Brønsted and Lewis acid sites. Extensive characterization such as MAS-NMR, XRD and in-situ DRIFTS confirmed that tin insertion induced reorganization of the clay layers into a disorganized houseof-cards structure. It also revealed that tin resided between the clay layers as defective $\mathrm{SnO}_{2}$ nanocrystals stabilized by the negative charge of MMT. The source of acidity in Sn-MMT was studied by comparing it with two similar materials, namely $\mathrm{Sn}(\mathrm{OH})_{4}$, and thermally treated Sn-MMT. Low activity measured for isolated hydroxylated $\mathrm{SnO}_{2}$ nanoparticles illustrates the importance of having clay and tin in close proximity. Meanwhile, deactivation upon thermal treatment occurred via sintering of the tin phase and diffusion of the protons inside the layers. Sn-MMT acidity is attributed to the combination of Si-OH-Al groups, formed as a by-product of $\mathrm{SnO}_{2}$ crystallization, and undercoordinated $\mathrm{Sn}$ surface sites, stabilized by the negative charge of MMT.
\end{abstract}

\section{Introduction}

Despite their higher efficiency, diesel cars suffer from excessive $\mathrm{NO}_{x}$ emissions which has contributed to their bad reputation. Polyoxymethylene dimethyl ethers (OME) are a new class of biofuel that were recently introduced as potential diesel additive or substitute. ${ }^{[1-3]}$ OME are oligomers composed of an oxymethylene chain capped by a methyl- and a methoxy-group, that drastically decreases the concentration of harmful pollutants in the exhaust gas (i.e. soot and $\mathrm{NO}_{x}$ ) when blended with diesel fuel. Introduction of the OME technology could thus alleviate diesel-related air pollution. OME synthesis involves a methyl and an oxymethylene source and leads to a large range of chain lengths, which follows the Schulz-Flory product distribution. The anhydrous synthesis route, with trioxane (TRI) and dimethoxymethane $\left(\mathrm{OME}_{1}\right)$, is known to generate the highest yield of OME (Scheme 1). ${ }^{[4]}$ Various catalysts such as zeolites,

[a] C. J. Baranowski, A. M. Bahmanpour, F. Héroguel, J. S. Luterbacher, O. Kröcher

Institute of Chemical Sciences and Engineering, École polytechnique fédérale de Lausanne (EPFL),

Route cantonale, 1015 Lausanne, Switzerland

[b] O. Kröcher

Paul Scherrer Institut

5232 Villigen PSI, Switzerland

oliver.kroecher@psi.ch; Tel +41 (0)56 3102066

Supporting information for this article is given via a link at the end of the document. acidic resins or ionic liquids have been used for this synthesis route. ${ }^{[5-8]}$ Solid acids have the intrinsic advantage of offering an easy separation compared to ionic liquids or mineral acids. It was found that both Brønsted ${ }^{[9,10]}$ and Lewis ${ }^{[11,12]}$ acidity catalyze OME synthesis. Currently, acidic resins and zeolite H-Beta have demonstrated the highest potential as catalyst for OME synthesis. ${ }^{[13,14]}$ However, acidic resins can deactivate due to thermal instability. ${ }^{[15]}$ Additionally, we demonstrated previously that H-ZSM-5 suffered from severe internal mass diffusion limitation, which could be circumvented by the addition of an auxiliary network of mesopores. ${ }^{[16]}$ Development of catalysts displaying a high number of accessible acidic sites is thus required for efficient OME synthesis.

Scheme 1. Synthesis of polyoxymethylene dimethyl ether (OME) from dimethoxymethane $\left(\mathrm{OME}_{1}\right)$ and trioxane $(\mathrm{TRI})$.

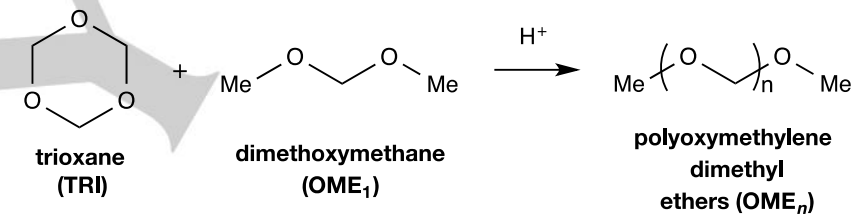

Meanwhile, clay has emerged over the past decades as a new type of cheap and eco-friendly material with versatile, high-end applications ranging from adsorbents to drilling fluids. ${ }^{[17,18]}$ It is capable of catalyzing a wide range of reactions such as addition, oxidation or dehydration. ${ }^{[19,20]}$ Its structure possesses advantageous features: it is composed of stacked aluminosilicate layers with intrinsic ion-exchange properties. Montmorillonite (MMT) is a 2:1 phyllosilicate clay with each layer composed of an octahedral alumina sheet sandwiched between two tetrahedral silica sheets. ${ }^{[21]}$ Isomorphous substitution by lower valence atoms such as $\mathrm{Ca}(\mathrm{II}), \mathrm{Al}(\mathrm{III})$ or $\mathrm{Mg}(\mathrm{II})$ in the aluminosilicate lattice generates a net negative charge counterbalanced by cations between the layers. These properties were leveraged to generate new types of structures such as delaminated clay or pillared layered clay (PILC), which are routinely used to catalyze various organic reactions. Notably, PILC can attain high accessible surface area with pore sizes larger than conventional zeolites. ${ }^{[22]}$ Introduction of tin by ion-exchange in MMT was recently shown to lead to a new catalytic material (Sn-MMT) following a simple procedure illustrated in Scheme 2. ${ }^{[23,24]}$ Its advantageous textural and acidic properties, as well as its ease of preparation compared to other tin-containing heterogeneous catalysts, lead to its applications in various organic reactions. Wang et al. reported that Sn-MMT displayed a highly superior activity than Sn-grafted MCM-41 for the cyanosilylation of ketones. ${ }^{[25]}$ They later found that its high specific surface area was formed by the intercalation of $\mathrm{SnO}_{2}$ nanoparticles between clay layers, resulting in strong 
Brønsted and Lewis acidity. ${ }^{[26-28]}$ Sn-MMT was also found to display a disorganized "house-of-cards" structure. ${ }^{[23]}$ The coexistence of acid sites was leveraged for various hemicellulose upgrading reactions: conversion of carbohydrates to 5(hydroxymethyl)furfural (HMF), ${ }^{[29]}$ HMF self-etherification, ${ }^{[24]}$ synthesis of alkyl lactates from triose ${ }^{[30]}$ and the production of furfural from xylose. ${ }^{[31]} \mathrm{Sn}-\mathrm{MMT}$ was also applied for the BaeyerVilliger oxidation. ${ }^{[32]}$

Scheme 2. Insertion of tin in between MMT layers.

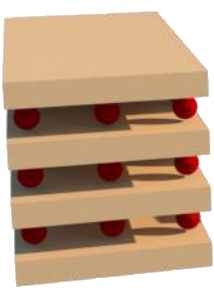

Na-MMT

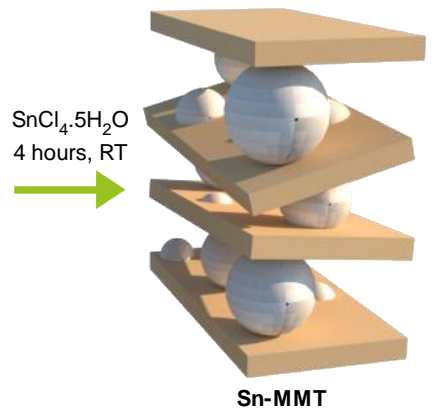

Sn-MMT
A reaction mechanism involving chain-like polymers of $\mathrm{SnO}_{2}$ in between the clay layers was suggested by Wang et al. ${ }^{[28]}$ Masui et al. estimated that the contact domain between clay layers and hydroxylated $\mathrm{SnO}_{2}$ nanoparticles was responsible for the material's catalytic activity. ${ }^{[23]}$ Finally, an isolated Sn species was also referred to by Hara et al. ${ }^{[32]}$ Despite this extensive research, the nature of Sn-MMT's acidity remains unclear. Therefore, this study aimed at elucidating its source of activity. Acid-treatment and insertion of tin were performed to introduce acidity in MMT. Activity of both catalysts for OME synthesis was subsequently assessed and compared with Amberlyst 36 (A36), a common acidic resin. From these results together with characterization data and control experiments, conclusions were drawn about the nature of the active sites in Sn-MMT.

\section{Results and Discussion}

First, the effects of tin insertion and acid-treatment (AT-MMT) on Na-MMT's structure and morphology are presented and discussed. Next, the activities of the synthesized catalysts for the production of OME are presented and compared to A36. The influence of reaction parameters is also analyzed for Sn-MMT, our best clay-based candidate. In order to clarify the nature of the active sites, we subsequently compare the activity of Sn-MMT to two similar materials, Sn-MMT-TT400 and tin hydroxide $\left(\mathrm{Sn}(\mathrm{OH})_{4}\right)$, which were similarly characterized. Finally, structureactivity relationships are discussed.

\section{Structure and morphology of Na-MMT, AT-MMT and Sn-MMT}

MMT possesses ordered units at different dimensions. ${ }^{[33]}$ The layer is the first unit with a thickness of around $1 \mathrm{~nm}$ and a lateral dimension between 1-2 $\mu \mathrm{m}$. The second unit consists of tactoids, which are several layers stacked onto each other in a turbostratic structure. Aggregates constitute the third unit and are composed of several tactoids with various arrangements that depend on different factors, including the nature of the interlayer cation.

Micropores can be present between layers (e.g. slit-shaped pores, lenticular-shaped) and mesopores generally arise from the presence of intertactoid pores. Clusters of aggregates may form interaggregates pores which are large mesopores to macropores. $\mathrm{N}_{2}$ physisorption was used to investigate the textural properties of the samples resulting from tin insertion and acid-treatment (Fig. 1a, Table S1, Supporting Information). It is important to note that $\mathrm{N}_{2}$ does not penetrate the interlayer space of unmodified MMT. ${ }^{[34]}$ All clays possessed a type II isotherm with an $\mathrm{H} 2$ hysteresis loop closing vertically at $\mathrm{p} / \mathrm{p}^{0}$ of 0.44 , which is typical for clay. Acidtreatment and insertion of tin increased the specific surface area from 69 to 119 and $269 \mathrm{~m}^{2} \cdot \mathrm{g}^{-1}$, respectively (Table S1). At low relative pressure, increased $\mathrm{N}_{2}$ uptake for AT-MMT and Sn-MMT indicated an increase in the microporous surface area $\left(\mathrm{S}_{\text {micro }}\right)$. The mesoporous surface area $\left(\mathrm{S}_{\text {meso }}\right)$ increased from 38 to 70 and 149 $\mathrm{m}^{2} \cdot \mathrm{g}^{-1}$ for AT-MMT and Sn-MMT, respectively. Acid-treatment of Na-MMT led to layer delamination (Fig. 1d) and to almost $90 \%$ replacement of interlayer $\mathrm{Na}^{+}$by $\mathrm{H}^{+}$(Table S2). Other cations present in the interlamellar space were also partly removed (e.g. $\left.\mathrm{K}^{+}, \mathrm{Ca}^{2+}\right)$. Mild clay dealumination was also observed, with its $\mathrm{Si} / \mathrm{Al}$ molar ratio going up from 2.98 to 3.13 . Furthermore, other substituting atoms (i.e. $\mathrm{Mg}^{2+}$ and $\mathrm{Fe}^{2+}$ ) were also partly removed by the acid treatment, as the $\mathrm{Si} / \mathrm{Mg}$ and $\mathrm{Si} / \mathrm{Fe}$ molar ratios increased from 17.13 to 20.61 and from 24.05 to 25.94 , respectively.

Meanwhile, despite Sn-MMT having a larger $S_{\text {meso }}$ compared to AT-MMT, it possessed a similar mesoporous volume, which could indicate the presence of interlayer tin. Sn-MMT possessed a broader distribution of small mesopores as well as fewer large mesopores (Fig. 1a, inset). ICP-OES analysis (Table S2) revealed that upon ion-exchange with $\mathrm{SnCl}_{4}, \mathrm{Sn}-\mathrm{MMT}$ reached 27.8 wt.\% of tin with only 660 ppm of sodium. SEM-EDX confirmed that tin was homogeneously distributed in the clay particles as no tin aggregation was detected (Fig. S2). The Si/Al molar ratio remained constant after tin insertion which indicates that no composition modifications occurred to the aluminosilicate sheets.

X-ray diffraction patterns (Fig. 1b) were used to investigate the clay structure and the nature of the tin phase. Na-MMT was identified with the $(00 /)$ reflection at $7.0^{\circ}, 14.2^{\circ}$ and $28.6^{\circ}$ as well as with the $(020,110)$ and $(200,130)$ reflections with maxima located at $19.9^{\circ}$ and $34.9^{\circ}$, respectively. ${ }^{[35,36]}$ The (001), (002) and (004) reflections of Sn-MMT almost disappeared showing a complete loss of the layered structure (confirming delamination) as well as a shift to lower diffraction angle, implying an increase in the mean interlayer distance from $1.24 \mathrm{~nm}$ to $1.31 \mathrm{~nm}$ (calculated using Bragg's law). ${ }^{[23,37]}$ A broad (001) basal reflection is observed for AT-MMT which hence only suffered from partial layer stacking loss and an increase in the mean interlayer distance to $1.45 \mathrm{~nm}$. Retention of the $(020,110)$ and $(200,130)$ reflections intensity suggested preservation of the twodimensional structure (i.e. the clay sheets) for both Sn-MMT and AT-MMT. ${ }^{[38]}$ 

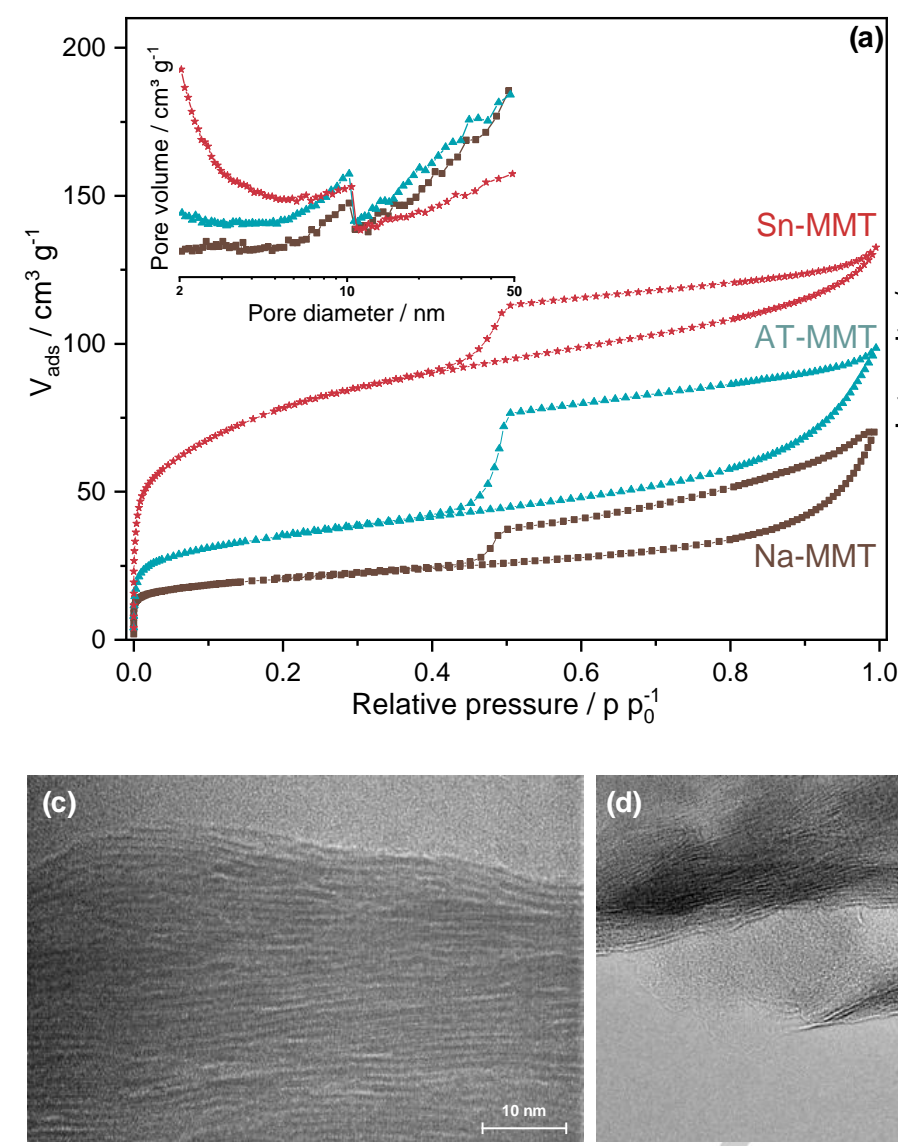
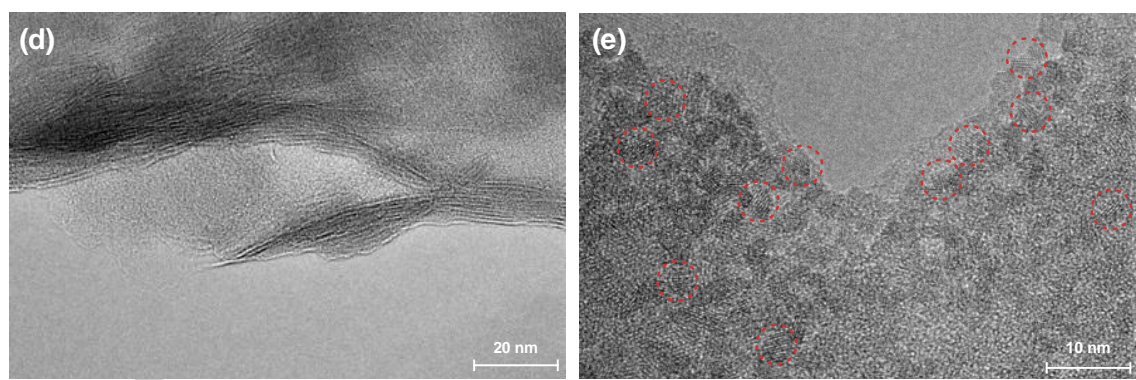

Fig. 1. (a) $\mathrm{N}_{2}$ isotherms of the catalyst samples and incremental pore volume determined using the BJH method (inset), (b) powder $X$-ray diffraction patterns of the catalyst samples ( ${ }^{*}$ indicates peak related to the sample holder) and TEM images of (c) Na-MMT, (d) AT-MMT, (e) Sn-MMT. Dotted circles are highlighting examples of lattice fringes observed for Sn-MMT.

Sn-MMT displayed diffraction peaks characteristic of a rutile-type $\mathrm{SnO}_{2}$ structure with broad peaks at $26.7^{\circ}$ and $34.8^{\circ}$, corresponding to the (110) and (101) reflections, respectively. ${ }^{[23]}$ The presence of broad peaks points to the formation of small, well-dispersed nanocrystals (below $5 \mathrm{~nm}$ ). Combined with the porosity results, we deduced that these crystals were inserted between the clay layers. Our results are thus in agreement with the report from Masui et al., stating that the presence of a nanocrystalline $\mathrm{SnO}_{2}$ phase changed the staking arrangement of tactoids into a disordered 'house-of-card' structure. ${ }^{[23]}$ Sn-MMT displayed the largest $\mathrm{S}_{\text {micro, }}$ as the presence of $\mathrm{SnO}_{2}$ nanocrystals likely induced the formation of additional interlayer microporous volume. The presence of interlayer $\mathrm{SnO}_{2}$ was confirmed by bright field transmission electron microscopy, where lattice fringe contrasts were observed (Fig. 1e). Due to the sensitive nature of the interlayer $\mathrm{SnO}_{2}$ particles, no elemental analysis study was performed, as prolonged exposure to the electron beam lead to aggregation of the $\mathrm{SnO}_{2}$ crystals. The presence of (110) and (101) $\mathrm{SnO}_{2}$ planes was confirmed by selected area electron diffraction (Fig. S3).
Diffuse reflectance infrared Fourier transform spectroscopy (DRIFTS) was carried out to gather additional information on the modifications of the clays (Fig. S4). Due to the diversity of structural groups present, interpretation of the curves can sometimes be intricate due to peak overlapping. Samples containing MMT displayed two peaks corresponding to structural hydroxyl groups bounded to octahedral $\mathrm{Al}$ in the $\mathrm{OH}$ stretching and bending regions, respectively at 3623 and $917 \mathrm{~cm}^{-1} .{ }^{[39]}$ Acidtreatment resulted in decrease of the peaks at 917,875 and 836 $\mathrm{cm}^{-1}$, assigned to bending vibrations of the hydroxyl groups $\left(\mathrm{Al}_{2} \mathrm{OH}\right),(\mathrm{AlFeOH})$ and $(\mathrm{AlMgOH})$, respectively. ${ }^{[38]} \mathrm{Mg}^{2+}$ was more prone to leaching upon acid-treatment than $\mathrm{Fe}^{3+} \cdot{ }^{[40]}$ The presence of chemisorbed and physisorbed water, most probably due to the hydration layer of the cations, was detected at $1630 \mathrm{~cm}^{-1}$ and $3423 \mathrm{~cm}^{-1}$. Additionally, The Si-O out-of-plane and in-plane stretching peaks were identified at 1110 and $995 \mathrm{~cm}^{-1}$, respectively. We observed a shift in both signals with the various treatments, which could be due to the change in the interlayer water content. These vibrations were independent of the nature or the concentration of the interlayer cation. ${ }^{[41]} \mathrm{A}$ detailed analysis of Sn-MMT spectrum is provided later. 

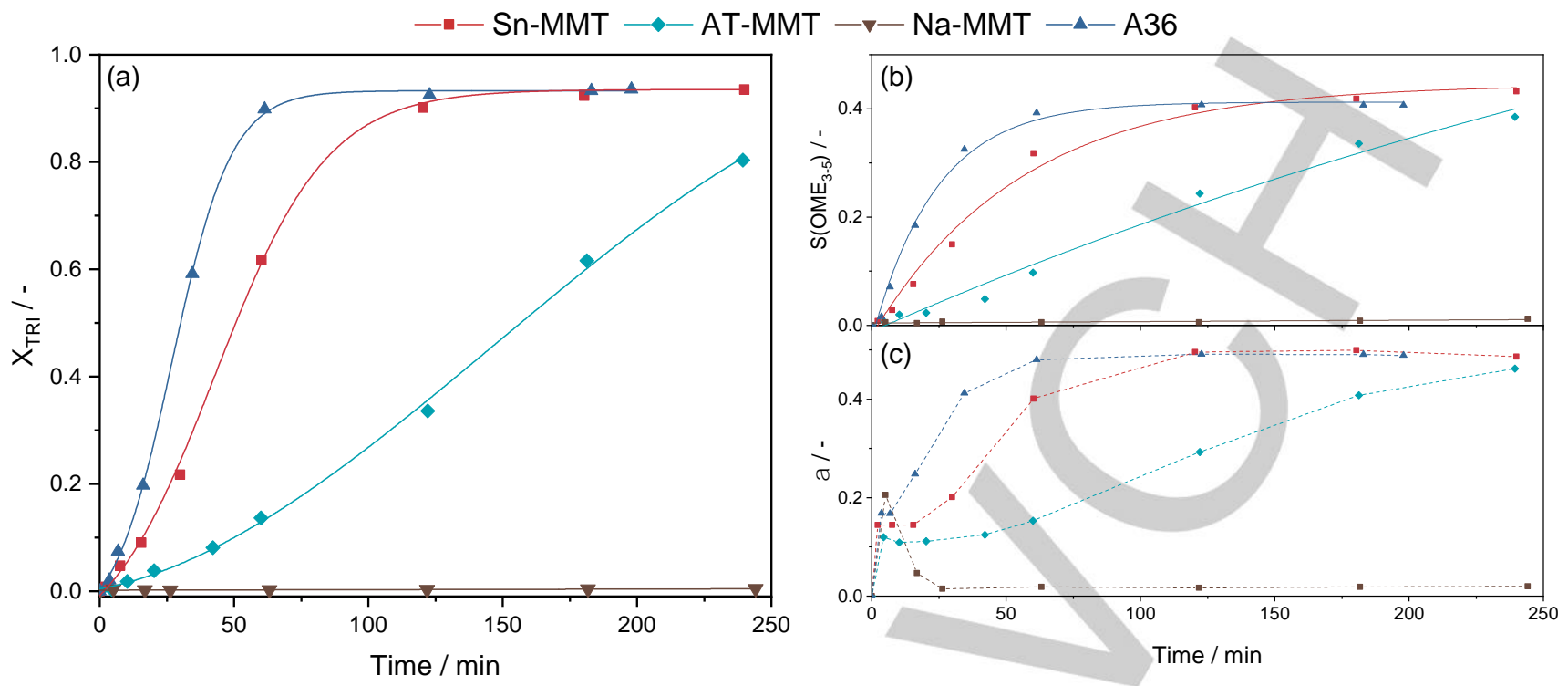

Fig. 2. (a) TRI conversion $X_{T R I}$, (b) selectivity to $\mathrm{OME}_{3-5} \mathrm{~S}\left(\mathrm{OME}_{3-5}\right)$ and (c) chain growth probability $\alpha$ for the production of $O M E$.

Magic angle spinning nuclear magnetic resonance (MAS-NMR) was used to investigate the local structure of $\mathrm{Si}$ and $\mathrm{Al}$ atoms. Natural MMT contains paramagnetic and/or ferromagnetic species that make MAS-NMR analysis difficult. ${ }^{[42]}$ Substitution of $\mathrm{Si}^{4+}$ by $\mathrm{Al}^{3+}$ in the tetrahedral sheet and substitution of $\mathrm{Al}^{3+}$ by $\mathrm{Mg}^{2+}$ in the octahedral sheet also induced broader peaks. ${ }^{27} \mathrm{Al}$ MASNMR (Fig. S5) shows two resonance peaks at ca. 70 and 5 ppm, which are attributed to four-fold $\mathrm{Al}^{(\mathrm{IV})}$ (tetrahedral sheet) and sixfold $\mathrm{Al}^{(\mathrm{VI})}$ (octahedral sheet), respectively. ${ }^{[42-44]}$ Overall, the proportion of $\mathrm{Al}^{(\mathrm{VI})}$ to $\mathrm{Al}^{(\mathrm{IV})}$ did not change significantly, indicating that the sheet structure stayed intact during acid-treatment or $\mathrm{SnCl}_{4}$ ion-exchange.

The ${ }^{29} \mathrm{Si}$ MAS-NMR spectrum of Na-MMT shows a broad peak corresponding to $\mathrm{Q}_{3}(\mathrm{OAI})$ (silicon atom connected to 3 silicon atoms via a basal oxygen and to the octahedral layer via an apical tricoordinated oxygen) (Fig. S6). The chemical shift of $Q_{3}(0 A)$ depends on the nature of the interlayer cation ${ }^{[4]}$ and shifts towards higher frequencies with a lower amount of $\mathrm{Na}^{+}$cations in the interlamellar space. Specifically, this peak appears at -90.5, 93.0 or $-93.8 \mathrm{ppm}$ for Na-MMT, AT-MMT and Sn-MMT, respectively. A shoulder centered at ca. $-83,-89$ or $-90 \mathrm{ppm}$ for Na-MMT, AT-MMT and Sn-MMT, respectively, corresponds to a $\mathrm{Q}_{3}(1 \mathrm{Al})$ moiety (silicon atom connected to 2 silicon and 1 aluminum atoms via bridging oxygens and to the octahedral sheet via an apical oxygen). ${ }^{[45]}$ Finally, the acid-treatment results in the appearance of a peak for $\mathrm{Q}_{3}(\mathrm{SiO} \equiv \mathrm{Si}-\mathrm{OH})$ due to dealumination.

\section{Catalytic properties for OME synthesis}

TRI conversion, selectivity towards $\mathrm{OME}_{3-5}$ as well as chain growth probability vs. time are displayed in Fig. 2 for various MMT samples and for A36. Their activities followed the trend: A36 > SnMMT > AT-MMT > Na-MMT. Na-MMT showed almost no TRI conversion but both treatments applied on the clay significantly improved its activity. AT-MMT possessed a modest activity while Sn-MMT performance was close to A36, our reference material. The latter reached equilibrium after 120 min of reaction while 180 min were necessary for Sn-MMT to achieve the same results. ATMMT did not reach equilibrium during the experimental run time. Sn-MMT led to a higher selectivity of 0.44 to $\mathrm{OME}_{3-5}$ at the end of the run compared to 0.41 using A36 (Fig. 2b). Both catalysts led to an equal value of $\alpha$, which reflects a chain length distribution that followed the SF distribution (Fig. 2c).

A more detailed study on the influence of reaction parameters was performed using Sn-MMT as the most active MMT-based candidate for the synthesis of OME (Fig. 3). Increase of the reaction temperature resulted in a lower TRI conversion and $\alpha$ value at equilibrium as expected for an exothermic reaction (Fig. 3a). Additionally, TRI conversion and $\alpha$ increased linearly with catalyst concentration (Fig. 3b). As expected, changing the molar ratio of $\mathrm{OME}_{1} / \mathrm{TRI}$ affected both TRI conversion and $\alpha$ at equilibrium (Fig. $3 c$ ): decreasing the ratio diminished the TRI conversion but increased $\alpha$, while an increase in the ratio resulted in higher TRI conversion with smaller $\alpha$. Indeed, increasing the proportion of TRI increases the OME chain length distribution at the expense of TRI conversion at equilibrium; this parameter thus needs to be optimized to maximize the production of $\mathrm{OME}_{3-5}$. Stability of Sn-MMT and A36 was also assessed during 4 successive runs (Fig. 3d) where comparable activities and no deactivation was observed. 

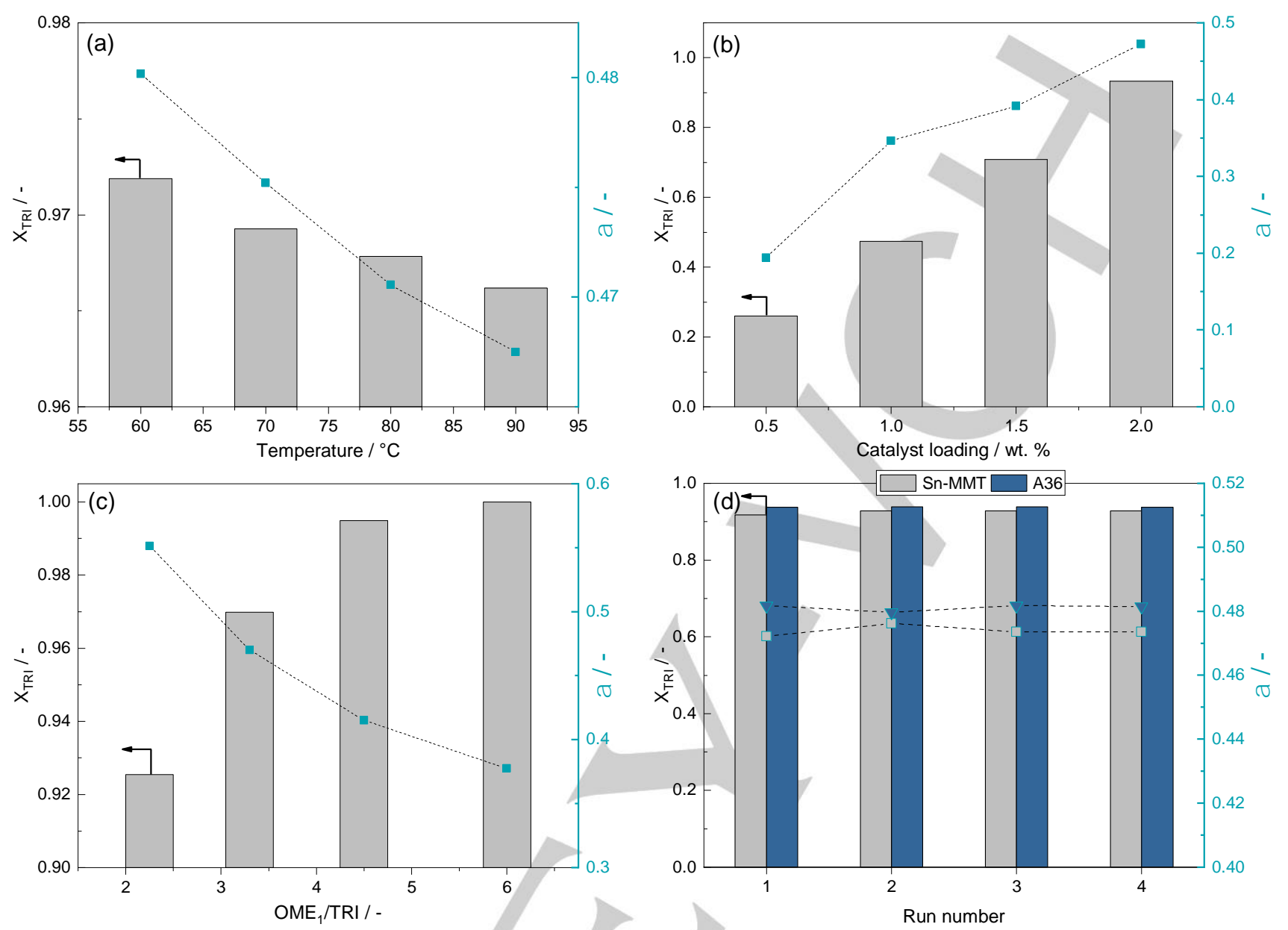

Fig. 3. OME synthesis from $\mathrm{OME}_{1}$ and $\mathrm{TRI}$. TRI conversion $\mathrm{X}_{\mathrm{TRI}}$ and chain growth probability $\alpha$ (a) at equilibrium for various temperature (0.5 wt. \% Sn-MMT, reaction time $240 \mathrm{~min}$ ), (b) at various $\mathrm{Sn}-\mathrm{MMT}$ wt. \% (reaction time $30 \mathrm{~min}$ ), (c) at equilibrium for different OME $1 / \mathrm{TRI}$ molar ratio $(0.5 \mathrm{wt}$. \% Sn-MMT, reaction time $240 \mathrm{~min}$ ) and (d) in a reusability test with A36 and Sn-MMT (1.0 wt. \%, reaction time $60 \mathrm{~min}$ ).

\section{Catalytic properties and characterization of $\mathrm{SnO}_{2}$ catalysts} In order to shed more light on the source of acidity of Sn-MMT, we studied the activity of two similar materials: Sn-MMT-TT400 (obtained after calcination at $400{ }^{\circ} \mathrm{C}$ for 3 hours of Sn-MMT) and tin hydroxide $\left(\mathrm{Sn}(\mathrm{OH})_{4}\right.$, synthesized by reduction of $\left.\mathrm{SnCl}_{4}\right)$. They help to understand the effect of calcination on the performance of $\mathrm{Sn}-\mathrm{MMT}$, and the interaction between clay and tin. Previous studies already used a similar comparison for a different reaction but failed to provide a detailed explanation on their lack of activity in comparison with Sn-MMT. ${ }^{[23,24]}$ As expected, both catalysts displayed much lower activity compared to Sn-MMT for the synthesis of OME from TRI and $\mathrm{OME}_{1}$ (Fig. 4). Thermal treatment showed a drastic effect on the TRI conversion with a drop of $92 \%$ while a TRI conversion of only $2.3 \%$ was reached using $\mathrm{Sn}(\mathrm{OH})_{4}$. A careful characterization of Sn-MMT-TT400 and $\mathrm{Sn}(\mathrm{OH})_{4}$ has been performed in order to build structure-activity relationships. Sn-MMT, Sn-MMT-TT400 and $\mathrm{Sn}(\mathrm{OH})_{4}$ displayed diffraction peaks characteristic of $\mathrm{SnO}_{2}$ structure (Fig. S7b) with average crystallite sizes of $2.74,4.82$ and $3.04 \mathrm{~nm}$, respectively (calculated based on the (001) reflection using Scherrer's equation). The thermal treatment of Sn-MMT slightly affected the $(020,110)$ and $(200,130)$ reflections, which could indicate a change in the clay layer crystal lattice. Additionally, $\mathrm{N}_{2}$ physisorption suggests sintering of $\mathrm{SnO}_{2}$ nanocrystals upon thermal treatment with a decrease in $S_{\text {micro }}$ while $S_{\text {meso }}$ remained rather constant (Table S1, Fig. S7a). $\mathrm{Sn}(\mathrm{OH})_{4}$ displayed a type I isotherm $\left(S_{\text {micro }}\right.$ of $75 \mathrm{~m}^{2} \cdot \mathrm{g}^{-1}$ and $\mathrm{S}_{\text {meso }}$ of $\left.46 \mathrm{~m}^{2} \cdot \mathrm{g}^{-1}\right)$ and confirms the high porosity of the tin hydroxide phase.

In order to get more insight into the deactivation mechanism of Sn-MMT during the thermal treatment, we performed in-situ DRIFTS of Sn-MMT at $400^{\circ} \mathrm{C}$ (Fig. 5). An increase in vibrations related to symmetric O-Sn-O and antisymmetric Sn-O-Sn stretching mode of a surface bridging oxide was observed at 669 and $737 \mathrm{~cm}^{-1}$, respectively, which is attributed to sintering of $\mathrm{SnO}_{2}$ nanocrystals. ${ }^{[46]}$ The peaks at 1327 and $1415 \mathrm{~cm}^{-1}$ are overtones of these two vibrations. Furthermore, we also observed a decrease of the signal between 850 and $950 \mathrm{~cm}^{-1}$ that corresponds to the hydroxyl bending region. 


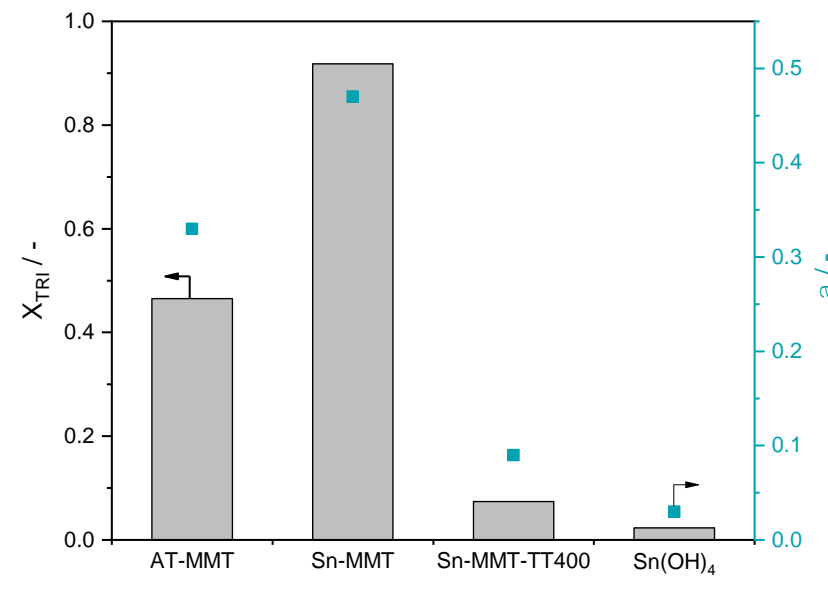

Fig. 4. TRI conversion $X_{T R I}$ and chain growth probability $\alpha$ for $A T-M M T, S n-M M T$, $\mathrm{Sn}-\mathrm{MMT}-\mathrm{TT} 400$ and $\mathrm{Sn}(\mathrm{OH})_{4}(1.0 \mathrm{wt}$. \% catalyst, reaction time $60 \mathrm{~min})$.

This phenomenon was ascribed by Alvero et al. to the migration of cations in vacant hexagonal holes of the silica sheet where they interact with structural hydroxyl groups. ${ }^{[47]}$ Meanwhile, analysis of the hydroxyl stretching region showed a decrease of a broad peak between 3300 and $3500 \mathrm{~cm}^{-1}$, which can be attributed to dehydration of the clay and/or condensation of $\mathrm{Sn}-\mathrm{OH}$ groups. No change was identified in the $\mathrm{Si}-\mathrm{OH}$ (ca. $3740 \mathrm{~cm}^{-1}$ ) and $\mathrm{Al}-\mathrm{OH}$ regions $\left(3640 \mathrm{~cm}^{-1}\right)$.

Comparison between ex-situ DRIFT spectra of Sn-MMT and SnMMT-TT400 shows a large difference in the intensity of the $\mathrm{OH}$ stretching region between 3500 and $3300 \mathrm{~cm}^{-1}$ due to irreversible desorption of both chemisorbed water and hydroxyl surface groups (Fig. S8). When the hydration shell of the proton is removed at high temperature, $\mathrm{H}^{+}$migrates in the clay sheet, thereby neutralizing its net charge, a phenomenon known as the Hofmann-Klemen effect. This was confirmed by a slight shift in the Si-O-Si stretching vibration which could result from lattice

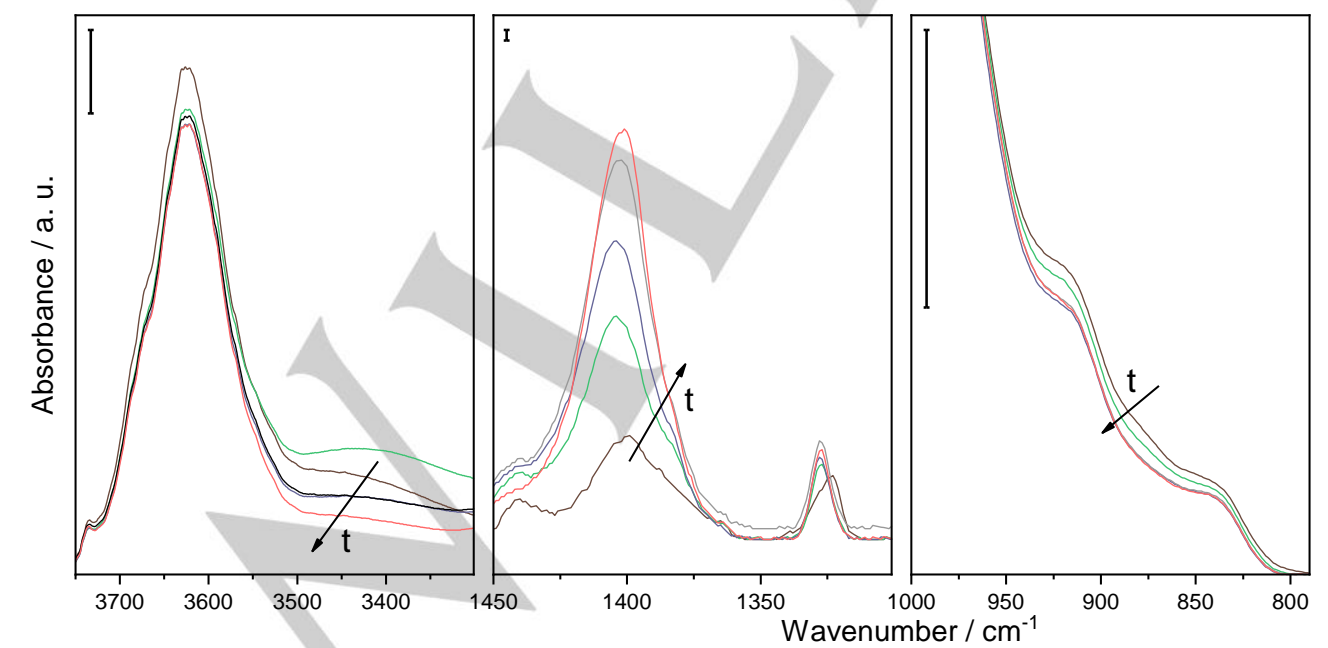

Fig. 5. In-situ DRIFT spectra of Sn-MMT treated at $400{ }^{\circ} \mathrm{C}$ under $20 \mathrm{~mL} \cdot \mathrm{min}^{-1}$ of He at various times (the scale bar on the top left of each frame indicates the relative intensity).

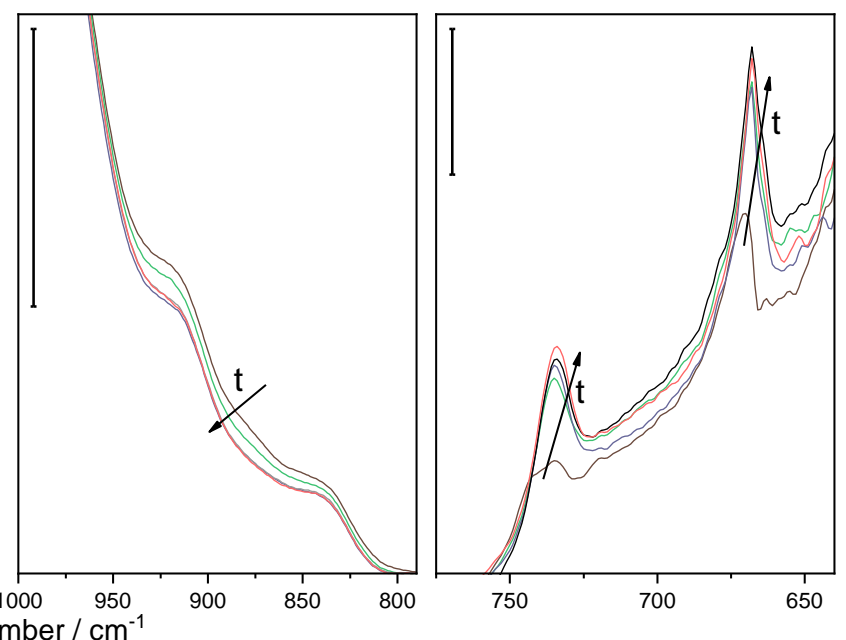
proton. ${ }^{[47]}$ This corroborates with the XRD patterns showing a weakening of the $(020,110)$ reflection. Furthermore, a similar decrease of the signal intensity between 850 to $950 \mathrm{~cm}^{-1}$ was observed compared to the in-situ DRIFTS measurements. The effect of the thermal treatment of the clay was also observed with ${ }^{27} \mathrm{Si}$ MAS-NMR spectroscopy showing a shift of the Q3(OAl) peak from -93.8 to $-95.1 \mathrm{ppm}$, which is attributed to the formation of a neutral structure (Fig. S6). ${ }^{[88]}$ Overall, it appeared that during the thermal treatment, the interlayer water was removed, dehydroxylated $\mathrm{SnO}_{2}$ nanocrystals sintered, and protons migrated inside the clay layers.

Meanwhile, analysis of $\mathrm{Sn}(\mathrm{OH})_{4}$ DRIFT spectrum shows a broad peak around $3440 \mathrm{~cm}^{-1}$ corresponding to the $\mathrm{O}-\mathrm{H}$ stretching vibration from the hydroxylated surface and molecular water, also responsible for the peak at $1630 \mathrm{~cm}^{-1}$ (Fig. S8). Saturation of the signal occurred at wavenumbers below $680 \mathrm{~cm}^{-1}$ due to the strong signal from Sn-O-Sn stretching vibration. ${ }^{[46]}$

The local structure of $\mathrm{Sn}$ was also investigated by ${ }^{119} \mathrm{Sn}$ MASNMR (Fig. 6a). All samples have similar signals with a main peak centered around $-604 \mathrm{ppm}$, which can be ascribed to octahedral tin in bulk $\mathrm{SnO}_{2} \cdot{ }^{[49]}$ No tetrahedral tin was detected. Variation of the main peak can be the result of hydroxylation of $\mathrm{SnO}_{2}$ surface and its crystalline size. ${ }^{[50]}$ Peak broadening indicates the presence shifts compared to bulk atoms. Hydroxylation of the tin surface was indicated by signals of the first and second tin layer which have chemical shifts of -590 and -615 ppm, respectively (Fig. 6a, inset). ${ }^{[23,51]}$ Sn-MMT-TT400 and Sn-MMT appear to have a slight signal shift towards lower values compared to $\mathrm{Sn}(\mathrm{OH})_{4}$. We suggest that this is caused by covalent anchoring of $\mathrm{Sn}$ atoms to the clay sheet to one or two silicon atoms via an oxygen bridge. ${ }^{[52]}$ Thermal treatment would thus also increase the number of covalent bonds between $\mathrm{SnO}_{2}$ and the tetrahedral silica sheet. A similar anchoring mechanism was observed for Al-pillared MMT upon thermal treatment. ${ }^{[22]}$ distortion of the Si-O framework due to the presence of the of $\mathrm{SnO}_{2}$ nanocrystals as surface atoms have different chemical 

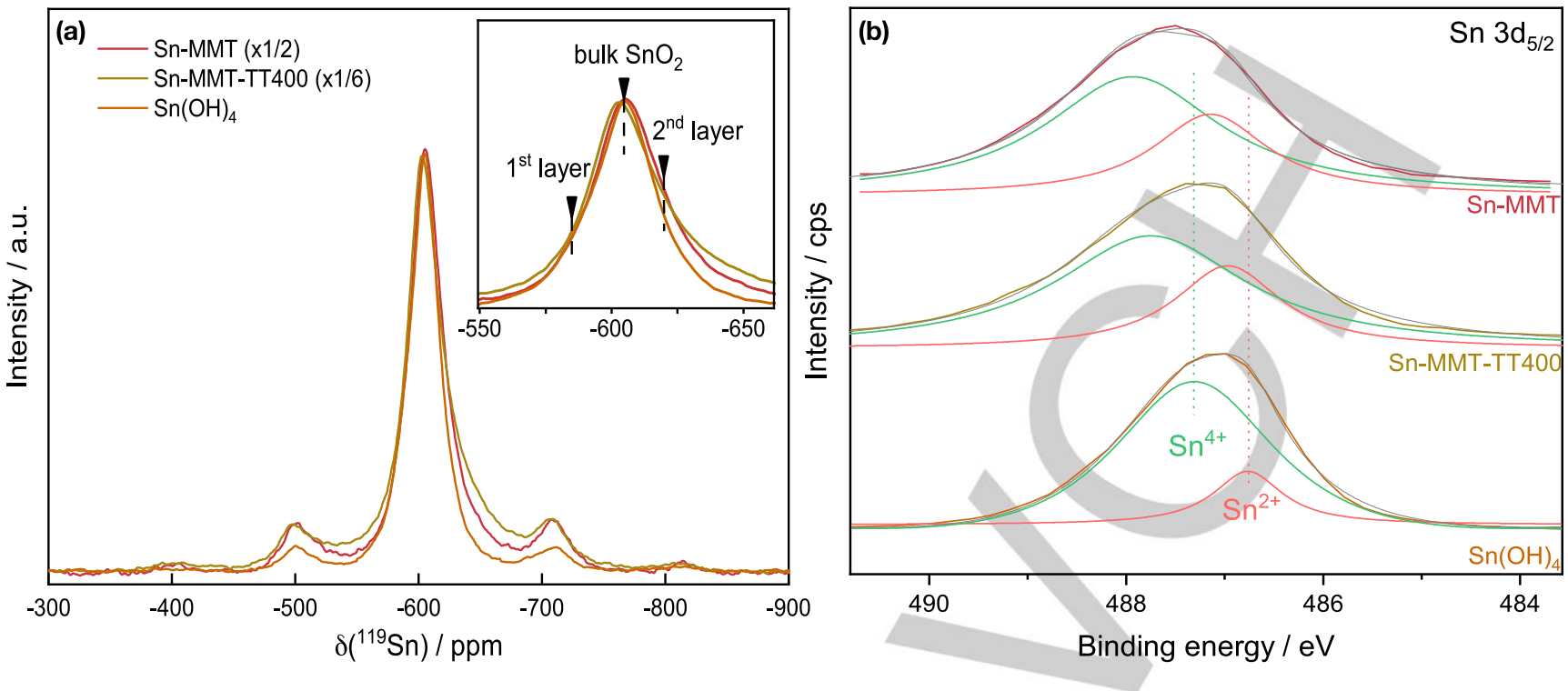

Fig. 6. (a) ${ }^{119} \mathrm{Sn}$ MAS-NMR spectra and enlarged view of the main peak (inset). (b) Deconvolution of the main XPS peak of Sn-MMT, Sn-MMT-TT400 and Sn(OH)4.

For further analysis of the oxidation states of the surface $\mathrm{SnO}_{2}$ species, we employed XPS which provides small probing depth in contrast to MAS-NMR (Fig. 6b). The high-resolution Sn $3 d_{5 / 2}$ XPS spectra of $\mathrm{Sn}(\mathrm{OH})_{4}$ were deconvoluted into two peaks attributed to $\mathrm{Sn}^{2+}$ and $\mathrm{Sn}^{4+}$, respectively centered at 486.8 and $487.3 \mathrm{eV} .{ }^{[53]}$ Fig. $7 \mathrm{~b}$ demonstrates that the tin prevalently existed as $\mathrm{Sn}^{4+}$ compared to $\mathrm{Sn}^{2+}$, which is an aliovalent substitution that require a charge compensation mechanism (i.e an oxygen vacancy). In comparison, tin species residing between the clay exhibited two differences: a higher proportion of $\mathrm{Sn}^{2+}$ and a shift of both peaks towards higher binding energies (Table S3). According to Yang et al., a shift towards higher binding energies reflects a surface with a higher amount of oxygen vacancies. ${ }^{[54]}$ Being positively charged, they cause a decrease in the electron density of nearby $\mathrm{Sn}$, and thus an increase in their binding energies. Thus, we suggest that the negative charge of the aluminosilicate layers induced a higher number of structural defects during crystallisation of $\mathrm{SnO}_{2}$ in the interlamellar space (i.e. $\mathrm{Sn}^{2+}$ and adjacent oxygen vacancies). Therefore, the activity of Sn-MMT could be due to a higher number of oxygen vacancies and adjacent undercoordinated $\mathrm{Sn}^{2+}$ atoms on the surface, which were also demonstrated to be more active in $\mathrm{NO}_{2}$ sensing. ${ }^{[55]}$ Thermal treatment of Sn-MMT resulted in a shift towards lower binding energy but did not affect the proportion of $\mathrm{Sn}^{2+} / \mathrm{Sn}^{4+}$. Compared to Sn-MMT, Sn-MMT-TT400 displayed thus a lower amount of undercoordinated surface Sn. Analysis of the O1s peak would not provide more information since it would also contain a large contribution from oxygen moieties present in the clay layer.

\section{Acidic properties of the catalysts}

Sample acidity was studied by $\mathrm{NH}_{3}$-TPD (Fig. 7a) and py-FTIR (Fig. 7b). The $\mathrm{NH}_{3}$-TPD profiles may not be perfectly reliable at temperature above $400{ }^{\circ} \mathrm{C}$ as structural changes may occur above this temperature. Acidity was measured by deconvolution of the $\mathrm{NH}_{3}$-TPD profiles and these values are presented in Table S1. While Na-MMT had very low acidity $\left(0.17 \mathrm{mmol} \cdot \mathrm{g}^{-1}\right)$, exchanging interlamellar $\mathrm{Na}^{+}$cations with $\mathrm{H}^{+}$(AT-MMT) increased its acidity to $0.31 \mathrm{mmol} \cdot \mathrm{g}^{-1}$. Thermal treatment of $\mathrm{Sn}-\mathrm{MMT}$ decreased acid site concentration from 0.71 to $0.51 \mathrm{mmol} \cdot \mathrm{g}^{-1}$ but did not alter the nature and strength of the acid sites with no difference observed by FTIR spectroscopy after saturation with pyridine vapour at $50^{\circ} \mathrm{C} .^{[56]}$ The typical bands for Brønsted (1530 and $1365 \mathrm{~cm}^{-1}$ ), Lewis (1451 and $1609 \mathrm{~cm}^{-1}$ ) and $\mathrm{H}$-bonded pyridine (1444 and $1596 \mathrm{~cm}^{-1}$ ) acidity were observed for Sn-MMT and Sn-MMT-TT400. The signal corresponding to Lewis acid sites remained constant with increasing temperatures, while the signal corresponding to Brønsted acid sites slightly diminished. Thus, both catalysts displayed strong Lewis acid sites and moderate Brønsted acidity. Meanwhile, weak and moderate Brønsted acidity were identified for Na-MMT and AT-MMT, respectively. Finally, $\mathrm{Sn}(\mathrm{OH})_{4}$ mostly displayed Lewis acid sites of moderate strength $\left(0.61 \mathrm{mmol} \cdot \mathrm{g}^{-1}\right)$. 

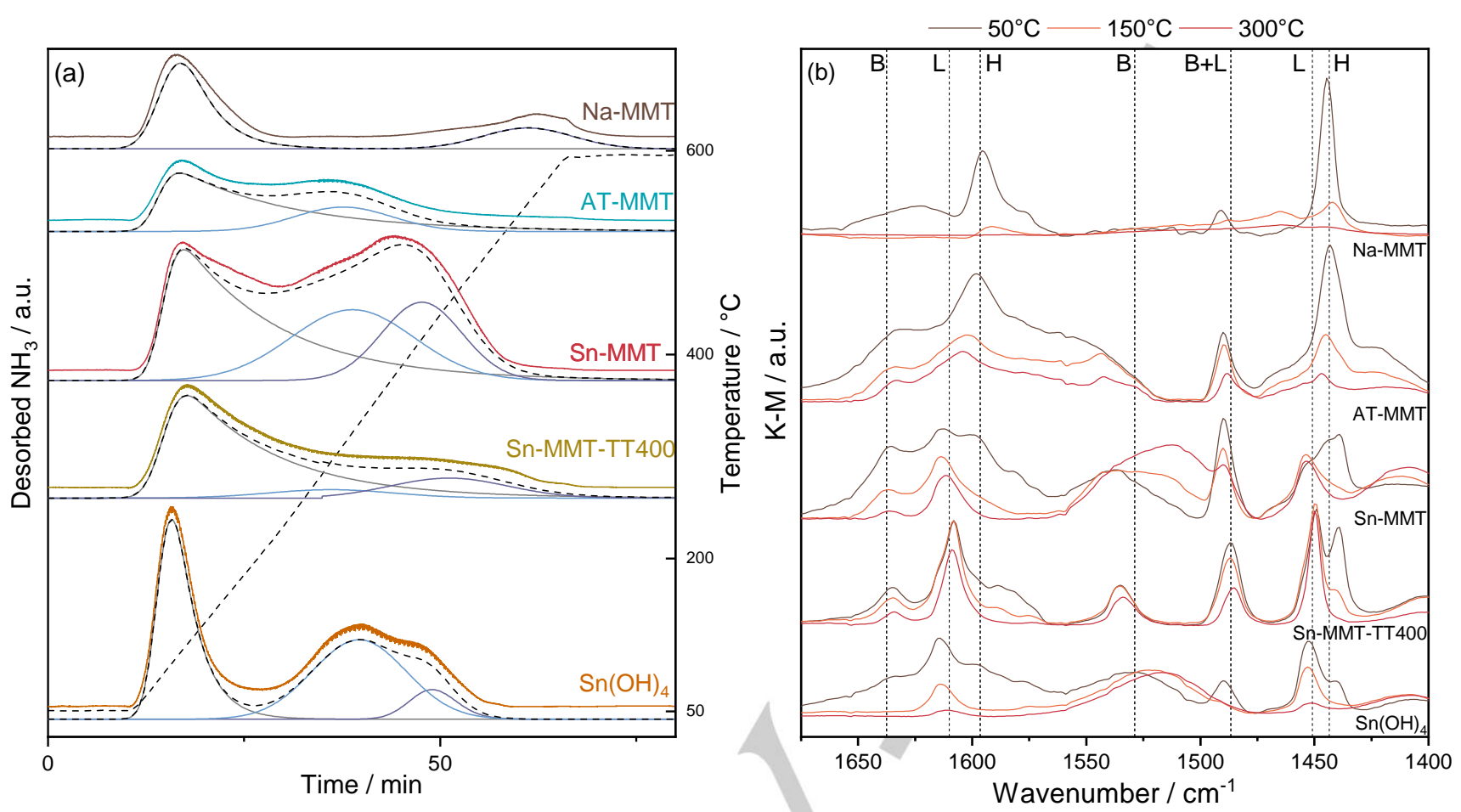

Fig. 7. Characterization of the acidity of the catalysts by (a) $\mathrm{NH}_{3}-\mathrm{TPD}$ and (b) pyridine-FTIR spectroscopy at various temperatures (B and $\mathrm{L}$ indicate pyridine bonded to Brønsted and Lewis sites, respectively, while $\mathrm{H}$ indicates $\mathrm{H}$-bonded pyridine).

\section{Discussion on the nature of the active site}

The characterization data obtained in this study helped to shed more light on Sn-MMT structure and active sites. Upon ionexchange with tin chloride, $\mathrm{SnO}_{2}$ nanocrystals were formed in between MMT layers by $\mathrm{Sn}^{4+}$ hydrolysis according to Equation Eq (1). As a result, clay layers were opened and exposed. Sn-MMT displayed a high surface area, as well as higher accessibility to strong acid sites due to the presence of micro- and mesopores.

$$
\mathrm{SnCl}_{4}+4 \mathrm{H}_{2} \mathrm{O}+4 \mathrm{Na}^{+} \rightarrow \mathrm{Sn}(\mathrm{OH})_{4}+4 \mathrm{NaCl}+4 \mathrm{H}^{+} \quad \text { Eq. (1) }
$$

Comparison of the catalytic activity of Sn-MMT, Sn-MMT-TT400 and $\mathrm{Sn}(\mathrm{OH})_{4}$ in OME synthesis, combined with the catalysts' characterization data allowed us to clarify the nature of the acid sites present in Sn-MMT (Scheme 3). The first question to answer is whether the acidity comes from the clay layer, the $\mathrm{SnO}_{2}$ nanocrystals, or both. First, since the activity of $\mathrm{Sn}(\mathrm{OH})_{4}$ was the lowest among these three catalysts, it is clear that the $\mathrm{SnO}_{2}$ nanocrystals have to be within the clay layers to efficiently catalyze OME synthesis. Surface $\mathrm{Sn}$ atoms acting as moderate Lewis acid and hydroxyl groups on the surface of the nanocrystals are insufficient to catalyze OME synthesis (Scheme 3a). Therefore, the proposal of Shinde et al. that hydroxylated $\mathrm{SnO}_{2}$ nanocrystals act as a source of Brønsted acidity is invalid. ${ }^{24]}$

Second, the clay layer is known to expose only weak Brønstedacidic silanols and weak Lewis acid sites (i.e. undercoordinated
$\mathrm{Al}^{3+}$ or $\mathrm{Mg}^{2+}$ at the edge of the clay sheet). Acidic protons could be produced during Equation Eq. (1) and stabilized by the clay layer (Scheme $3 \mathrm{~b}$ ). These protons could migrate into the clay layer during the thermal treatment, neutralizing the clay positive charge and reducing its acidity. However, these acidic protons are known to be of moderate strength. ${ }^{[57]}$

Similar to pillaring of MMT with aluminum, we thus suggest that acidity is most probably linked to the combination of $\mathrm{SnO}_{2}$ and the clay layers. Depending on the coordination and environment of $\mathrm{Sn}$, several scenarios are possible. First, isolated, fourfoldcoordinated Sn bound to $3 \mathrm{O}-\mathrm{Si}$ and one hydroxyl group could be the source of its acidity where $\mathrm{SnO}_{2}$ nanocrystals would only serve as pillars to increase the surface area of MMT (Scheme 3c). Thermal treatment would cause them to migrate and coalesce with the $\mathrm{SnO}_{2}$ nanocrystals and hence to lose their activity. However, fourfold-coordinated tin atoms were not detected by ${ }^{119}$ Sn MAS-NMR.

Secondly, interfacial Sn atoms, anchored to the clay layer, could act as the source of Brønsted acidity (Scheme 3d). However, it would be rather unlikely that surface Sn could act both as crosslinking point to the clay layers as well as acid sites. Only four-fold coordinated Sn, present on high energy facets such as the (111) and the (221) facets, could simultaneously coordinate to the clay layer and a hydroxyl group. Furthermore, access to these sites to OME molecules would be rather difficult. 

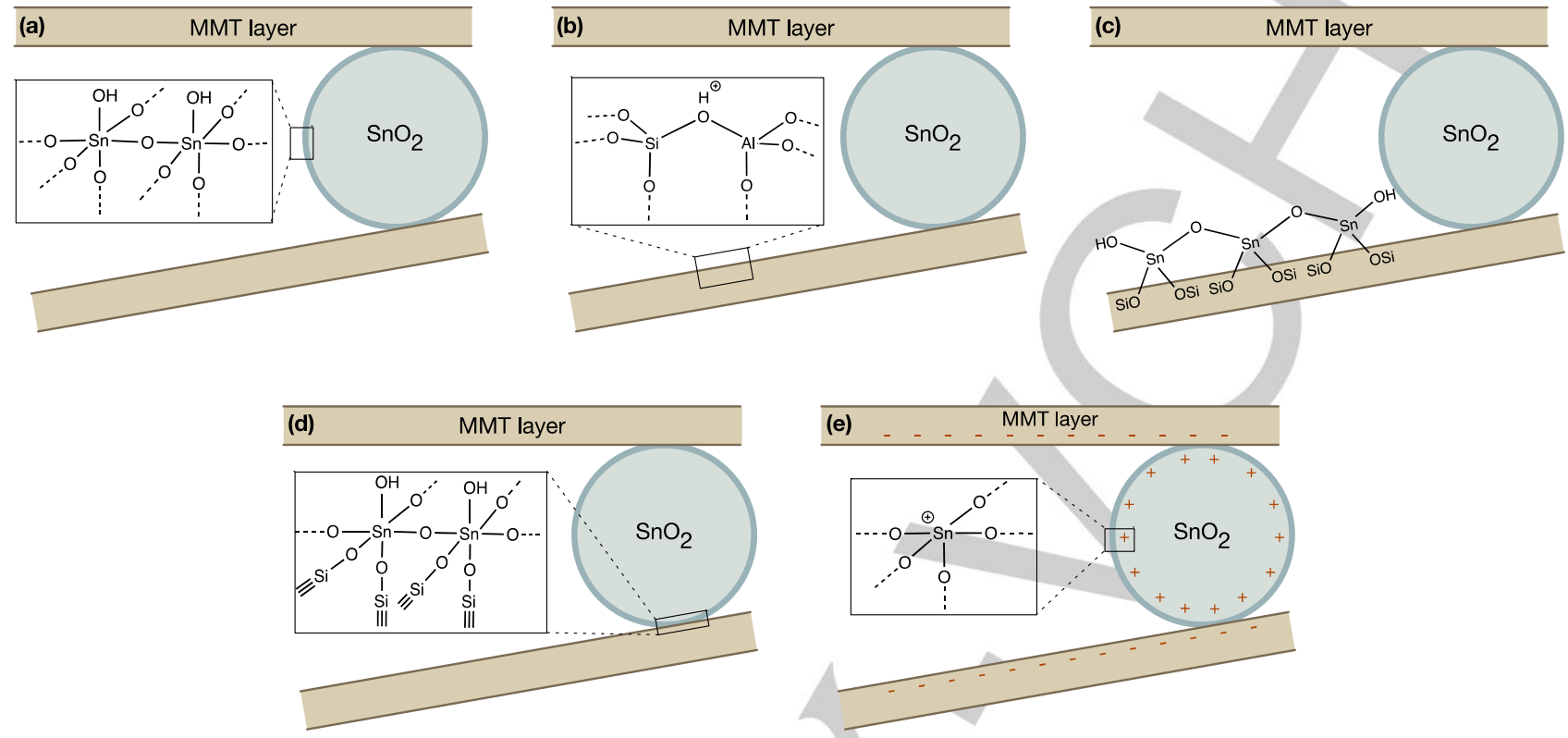

Considering ${ }^{119}$ Sn MAS-NMR and XPS data, showing that clay stabilized the formation of defective $\mathrm{SnO}_{2}$ nanocrystals displaying a higher number of undercoordinated surface $\mathrm{Sn}^{2+}$ atoms, we believe that these defects act as strong Lewis acid sites (Scheme 3e). Undercoordinated surfaces sites of nanocrystals are electron deficient and are known to display a Lewis-acidic character. ${ }^{[58]}$ Thermal treatment of Sn-MMT would cause sintering of the $\mathrm{SnO}_{2}$ nanocrystals and migration of $\mathrm{H}^{+}$inside the clay. The resulting catalyst would contain neutral $\mathrm{SnO}_{2}$ nanocrystal devoid of its acidity.

Acidity characterization showed that strong Lewis and moderate Brønsted acid sites were present. Furthermore, it demonstrated that thermal treatment affected mostly the acid site concentration. Therefore, we suggest that the source of Sn-MMT acidity is a combination of: (1) Si-OH-Al groups, produced during the crystallization of $\mathrm{SnO}_{2}$ by the release of $\mathrm{HCl}$ (Scheme 3b) and (2) strong Lewis acid sites at the $\mathrm{SnO}_{2}$ surface formed by undercoordinated $\mathrm{Sn}^{2+}$ surface atoms stabilized by the negative charge of the clay layer (Scheme 3e). The presence of both Lewis and Brønsted acid sites explains the observed high activity of SnMMT for OME synthesis. Liu et al. recently suggested a synergistic effect of Brønsted and Lewis acid sites for the synthesis of OME from paraformaldehyde and $\mathrm{OME}_{1} \cdot{ }^{[59]}$ The Lewis acidity in $\mathrm{Sn}(\mathrm{OH})_{4}$ alone was insufficient to catalyze OME synthesis, while the Brønsted acidity in AT-MMT resulted in only moderate activity. Besides acidity, the presence of both microand mesopores in Sn-MMT also allowed enhanced mass transport for bulky OME molecules.

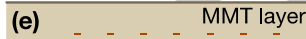

(e)

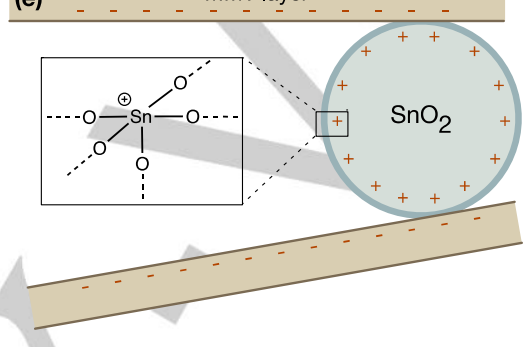

\section{Conclusions}

We reported that tin incorporation into clay-based materials boost the catalytic activity for OME synthesis to reach similar performances compared to reference acidic resins. Based on detailed characterization, we gained insights into Sn-MMT active sites nature: upon ion-exchange with $\mathrm{SnCl}_{4}, \mathrm{SnO}_{2}$ nanocrystals were formed and expanded the MMT layers to produce accessible Brønsted and Lewis acid sites, leading to a disorganized houseof-cards structure. Control experiments revealed that hydroxylated tin oxide alone is a poor catalyst for OME synthesis. Moreover, Sn-MMT deactivates by losing its acidity upon thermal treatment, which occurs via successive dehydration, sintering of the $\mathrm{SnO}_{2}$ phase and migration of protons within the clay layers. $\mathrm{Sn}-\mathrm{MMT}$ acidity is attributed to $\mathrm{Si}-\mathrm{OH}-\mathrm{Al}$ group, formed as a byproduct of $\mathrm{SnO}_{2}$ crystallization, and undercoordinated, defective $\mathrm{SnO}_{2}$ surface sites. The negative charge generated by the MMT layers is key in stabilizing these surface defects, which act as strong Lewis acid sites. In conclusion, our work thus identifies the active sites present in Sn-MMT and provides a first instance of clay-based catalysts for the synthesis of OME.

\section{Experimental Section}

Chemicals and materials synthesis 
All reagents were of analytical grade and obtained from commercial suppliers. No further purification was done unless specified otherwise. Sodium-exchanged montmorillonite (Na-MMT) was purchased from Fluorochem. Trioxane (99\%), dimethoxymethane $(99.0 \%), \mathrm{SnCl}_{4} \cdot 5 \mathrm{H}_{2} \mathrm{O}$ and Amberlyst 36 (A36) were obtained from Sigma Aldrich. $\mathrm{OME}_{2}$ to $\mathrm{OME}_{6}$ $(99.0 \%)$ were purchased from ASG Analytics.

\section{Acid- and tin chloride treatment}

The acid-treated montmorillonite (AT-MMT) was prepared as described in a protocol given by Beloufa et al. ${ }^{[60]}$ Crushed clay $(30 \mathrm{~g})$ was dispersed in $120 \mathrm{~mL}$ of Deionized water and the mixture was stirred for $2 \mathrm{~h}$ at room temperature in an Erlenmeyer flask. Then, $100 \mathrm{~mL}$ of a $0.5 \mathrm{M}$ sulfuric acid aqueous solution was added. The solution was maintained for 2 days under stirring at room temperature. The mixture was then filtered and washed with distilled water until $\mathrm{pH} 7$ was reached. Finally, the product was dried for $24 \mathrm{~h}$ at $110^{\circ} \mathrm{C}$ and crushed in a mortar.

Sn-MMT was prepared as described in a protocol given by Shinde et al. ${ }^{[24]}$ Na-MMT $(5.0 \mathrm{~g})$ was stirred at room temperature in $80 \mathrm{~mL}$ of a $0.3 \mathrm{M}$ aqueous $\mathrm{SnCl}_{4}$ solution for $4 \mathrm{~h}$. The clay was then collected by filtration and washed with distilled water until a $\mathrm{pH} 7$ was reached. The product was then dried for $24 \mathrm{~h}$ at $110^{\circ} \mathrm{C}$ and crushed in a mortar. Sn-MMT-TT400 was obtained by thermal treatment of Sn-MMT at $400{ }^{\circ} \mathrm{C}$ for $3 \mathrm{~h}$ under static air with a temperature ramp of $5{ }^{\circ} \mathrm{C} \cdot \mathrm{min}^{-1}$. Hydroxylated $\mathrm{SnO}_{2}$ nanoparticles (denoted as $\mathrm{Sn}(\mathrm{OH})_{4}$ ) were prepared by hydrolysis of $\mathrm{Sn}^{4+}$ in a basic aqueous solution, by mixing a $\mathrm{SnCl}_{4}$ aqueous solution $(0.3 \mathrm{M}, 100 \mathrm{~mL})$ with $30 \%$ aqueous ammonia $(26 \mathrm{~mL})$ at room temperature. ${ }^{[61]}$ The white precipitate was filtered and dried at $110^{\circ} \mathrm{C}$ overnight.

\section{Material Characterization}

$\mathrm{N}_{2}$ physisorption experiments were performed on a Micrometrics 3 Flex apparatus at liquid nitrogen temperature and $\mathrm{N}_{2}$ relative pressures between $10^{-5}$ and 0.99 . Typically, samples (ca. $150 \mathrm{mg}$ ) were dried at $120{ }^{\circ} \mathrm{C}$ (temperature ramp $5^{\circ} \mathrm{C} \cdot \mathrm{min}^{-1}$ ) for $5 \mathrm{~h}$ under vacuum. A leak test was performed before the analysis. Brunauer-Emmett-Teller (BET) surface, Barrett-Joyner-Helenda (BJH) and t-plot method were used to calculate the specific surface area, the mesoporous and microporous volume, respectively.

Elemental analyses were performed using inductively coupled plasma optical emission spectrometry (ICP-OES) at the Paul Scherrer Institute on a Vista pro AX Varian instrument. Clays were dissolved using a 1:2:2:2 mixture of $\mathrm{HCl}\left(30\right.$ wt. \%), $\mathrm{HNO}_{3}\left(65\right.$ wt. \%), $\mathrm{H}_{2} \mathrm{SO}_{4}$ (96 wt. \%) and $\mathrm{HF}(40$ wt. \%). XPS spectra were measured on a PHI VersaProbe II scanning XPS microprobe (Physical Instruments AG, Germany) with a monochromatic Al $\mathrm{Ka} \mathrm{X}$-ray source of $24.8 \mathrm{~W}$ power and a $100 \mu \mathrm{m}$ beam size.

X-ray diffraction (XRD) patterns were recorded using a D8 advance Bruker instrument equipped with a $1 \mathrm{D}$-LynxEye detector (Cu Ka radiation, no monochromator, Ni filter) with a step size of $0.01^{\circ}$. Structure of the sample was observed by transmission electron microscopy (TEM) on a FEI Tecnai Osiris with $200 \mathrm{kV}$ acceleration voltage. Grids were prepared by deposition of a drop of ethanol suspension ( $99.8 \%$, Fisher Chemical) containing the sample on a Lacey carbon grid. Scanning Electron Microscopy (SEM) was performed on a Zeiss Gemini SEM 300 electron microscope with acceleration voltage of $3 \mathrm{kV}$ and with Everhart-Thornley secondary electron detector to study the morphology of the clay particles. For EDX analysis, the microscope was equipped with an Oxford detector X-max ${ }^{N}$ and EDX measurements were performed by means of AZtec software. To acquire $X$-rays signal from all elements present in the sample, an e-beam acceleration voltage of $6 \mathrm{kV}$ was applied.
Magic angle spinning nuclear magnetic resonance (MAS-NMR) was used to study the coordination and chemical environment of $\mathrm{Al}, \mathrm{Si}$ and $\mathrm{Sn} .{ }^{27} \mathrm{Al}$ and ${ }^{29} \mathrm{Si}$ spectra were collected on a $400 \mathrm{MHz}$ Bruker Avance III HD spectrometer with a spinning rate of 35 and $15 \mathrm{kHz}$, respectively. ${ }^{119} \mathrm{Sn}$ spectra were recorded at room temperature on a $500 \mathrm{MHz}$ Bruker instrument equipped with a $11.7 \mathrm{~T}$ magnet (proton frequency) with a spinning rate of $20 \mathrm{kHz}$. All spectra were recorded at $298 \mathrm{~K}$ with a singlepulse and the typical acquisition was 1024 scans. ${ }^{1} \mathrm{H}$ MAS-NMR was also performed but did not provide reproducible results and is therefore not included.

The concentration of acid sites was calculated from $\mathrm{NH}_{3}$ temperature programmed desorption ( $\mathrm{NH}_{3}$-TPD) experiments using a Micromeritics Autochem 2920 II instrument. Typically, the sample (ca. $100 \mathrm{mg}$ ) was loaded in a U-shaped quartz cell and dried with a He flow $\left(50 \mathrm{~mL} \cdot \mathrm{min}^{-1}\right)$ at $200{ }^{\circ} \mathrm{C}\left(2^{\circ} \mathrm{C} \cdot \mathrm{min}^{-1}\right.$; hold time of $\left.120 \mathrm{~min}\right)$. Saturation of the sample with $\mathrm{NH}_{3}$ was done using a 1:99 $\mathrm{NH}_{3}: \mathrm{He}$ (volumetric ratio) flow during $1 \mathrm{~h}$ at $50{ }^{\circ} \mathrm{C}$. Physisorbed $\mathrm{NH}_{3}$ was then removed with $\mathrm{He}\left(50 \mathrm{~mL} \cdot \mathrm{min}^{-1}\right)$. The temperature was then increased to $600{ }^{\circ} \mathrm{C}\left(10{ }^{\circ} \mathrm{C} \cdot \mathrm{min}^{-1}\right)$ and $\mathrm{NH}_{3}$ desorption was monitored using a calibrated MKS Cirrus II mass spectrometer (mass 16).

Diffuse reflectance infrared Fourier transform spectroscopy (DRIFTS) was performed on a high temperature Harrick DRIFT cell mounted on a Perkin Elmer Frontier spectrometer equipped with a mercury cadmium telluride detector. Ex-situ spectra were recorded with 32 scans at a resolution of 4 $\mathrm{cm}^{-1}$ after being dried $2 \mathrm{~h}$ at $200{ }^{\circ} \mathrm{C}$ under a He flow of $20 \mathrm{~mL} \cdot \mathrm{min}^{-1}$. Pyridine adsorption experiments were performed using the following procedure: first, the sample was dried and consequently saturated with pyridine vapor at $50^{\circ} \mathrm{C}$ for $30 \mathrm{~min}$ under a He flow of $20 \mathrm{~mL} \cdot \mathrm{min}^{-1}$ bubbling through pyridine at room temperature. Physisorbed pyridine was then removed by flowing pure $\mathrm{He}\left(20 \mathrm{~mL} \cdot \mathrm{min}^{-1}\right)$ for $30 \mathrm{~min}$. Finally, the temperature was raised to 150 and $300^{\circ} \mathrm{C}$ with a ramp rate of $5^{\circ} \mathrm{C}^{-1}$.

\section{Catalytic tests}

Synthesis of OME were performed in two setups described in Fig. 8. The first is a $450 \mathrm{~mL}$ stirred batch reactor manufactured in 316 stainless steel under a pressure of $5 \mathrm{bar}$ of Ar. Typically, $30.83 \mathrm{~g}$ of TRI and $85.93 \mathrm{~g}$ of $\mathrm{OME}_{1}$ were loaded followed by 3 purges of Ar prior to mixing and heating the mixture to the reaction temperature (Fig. 8a). The temperature and pressure were measured respectively with a J-type thermocouple and a membrane pressure gauge. The reactor was thermostated with an electrically heated jacket. A stirring speed of $450 \mathrm{rpm}$ was used. Samples $(0.3 \mathrm{~mL})$ were taken from the bottom of the reactor using a sample valve composed of a dip tube and a heat exchanger to cool the samples at $30^{\circ} \mathrm{C}$. Catalyst injection was performed using a pressurized solid charging system and was considered the start of the reaction.

The second setup was composed of glass reactors (Grace, $10 \mathrm{~mL}$ ) with PTFE screw caps and a silicon sealing disk (Fig. 8b) heated by an aluminum block with holes using a magnetic stirring (450 rpm). After loading with the reactants and catalyst, the reactors were inserted into the aluminum block, which was considered as the start of the reaction. A sample was taken after quenching the reactors in an ice bath. Unless mentioned otherwise, all experiments were conducted at $70{ }^{\circ} \mathrm{C}$ with a $\mathrm{OME}_{1} / \mathrm{TRI}$ molar ratio of 3.3 and 0.5 wt. \% of catalyst. A catalyst loading of $1.0 \mathrm{wt}$. \% was used for the reusability test with a reaction time of $60 \mathrm{~min}$. Tests that required to reach equilibrium were performed during $240 \mathrm{~min}$ with a 0.5 wt. \% catalyst loading. 


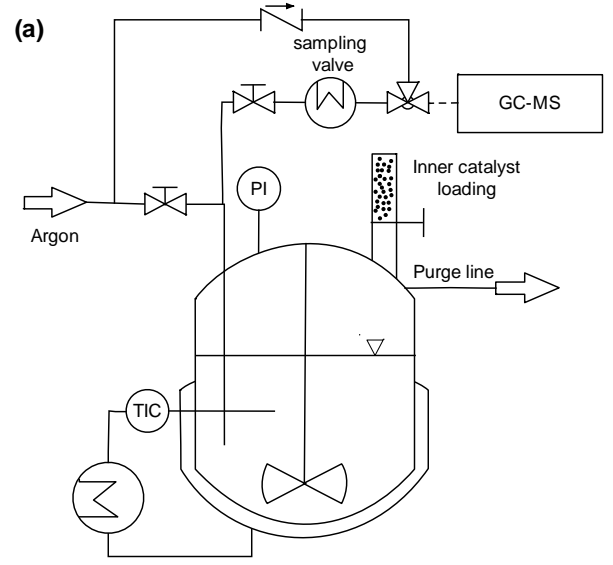

(b)

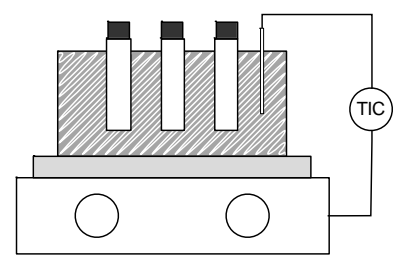

Fig. 8. Schematic of (a) the $450 \mathrm{~mL}$ stirred batch reactor and (b) glass reactors in the aluminum block on a stirring plate. PI: pressure indicator. TIC: temperature indicator and control. PIC: pressure indicator and control.

An Agilent 7890B/5977A series gas chromatography mass spectrometer (GC-MS) was used for the analysis of the liquid samples. It was equipped with an HP-5 capillary column (length $30 \mathrm{~m}$, outer diameter $0.32 \mathrm{~mm}$, film $1.05 \mu \mathrm{m})$ and an automated liquid sampler. A dean switch was used to send the eluent to a Flame Ionization Detector (FID) or to the mass spectrometer. $\mathrm{OME}_{1-6}$, methanol and methyl formate were quantified using a calibration curve. $\mathrm{OME}_{7-8}$ calibration curves were constructed based on the effective carbon number method and an extrapolation of the detector response from $\mathrm{OME}_{1-6 .}{ }^{[62]}$ Conversion of trioxane $\left(\mathrm{X}_{\mathrm{TRI}}\right)$, selectivity to $\mathrm{OME}_{3-5}\left(\mathrm{~S}\left(\mathrm{OME}_{3-5}\right)\right)$ and growth probability $(\alpha)$ were used to quantify the performance of the catalysts for the synthesis of OME and were defined as:

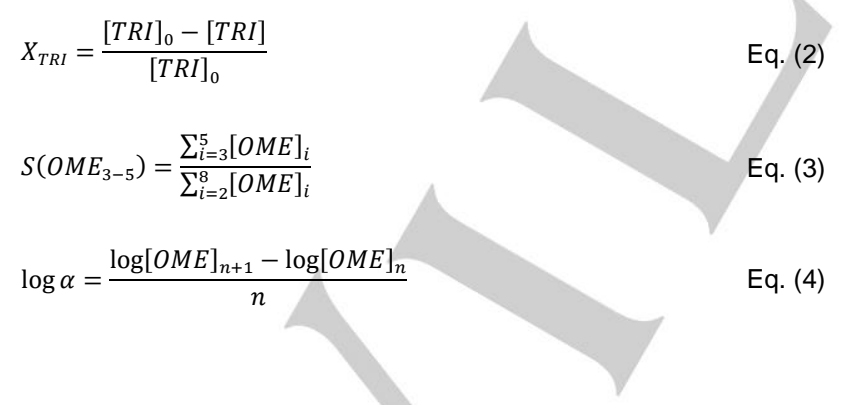

\section{Acknowledgements}

This research project is financially supported by the Swiss Innovation Agency Innosuisse and is part of the Swiss Competence Center for Energy Research SCCER BIOSWEET. The authors are grateful to Vincent Dufoulon for his work as well as Martin Elsener, Emilie Baudat, Lucie Navratilova, Snaedis Bjoergvinsdottir and Pascal Schouwink for help characterizing our samples. Florent Héroguel and Jeremy S. Luterbacher acknowledge funding from the Swiss National Science Foundation through grant PYAPP2_154281.

Keywords: Polyoxymethylene dimethyl ethers • oxygenated fuel - tin • clays $\cdot$ hierarchical material

[1] B. Lumpp, D. Rothen, C. Pastötter, R. Lämmermann, E. Jacob, MTZ 2011, 72, 34-39.

[2] J. Burger, M. Siegert, E. Ströfer, H. Hasse, Fuel 2010, 89, 33153319 .

[3] E. Jacob, W. Maus, MTZ Worldw. 2017, 3

[4] K. Hackbarth, P. Haltenort, U. Arnold, Chem. Ing. Tech 2018, 90, 1520-1528.

[5] J. Burger, E. Ströfer, H. Hasse, Ind. Eng. Chem. Res. 2012, 51, 12751-12761.

[6] Q. Zhao, H. Wang, Z. Qin, Z. Wu, J. Wu, W. Fan, J. Wang, J. Fuel Chem. Technol. 2011, 39, 918-923.

[7] L. Wang, W.-T. Wu, T. Chen, Q. Chen, M.-Y. He, Chem. Eng. Commun. 2014, 201, 709-717.

[8] C. J. Baranowski, A. M. Bahmanpour, O. Kröcher, Appl. Catal. B Environ. 2017, 407-420.

[9] H. Li, H. Song, L. Chen, C. Xia, Appl. Catal. B Environ. 2015, 165, 466-476.

[10] Y. Zheng, Q. Tang, T. Wang, Y. Liao, J. Wang, Chem. Eng Technol. 2013, 36, 1951-1956.

[11] Z. Xue, H. Shang, Z. Zhang, C. Xiong, C. Lu, G. An, Energy \& Fuels 2016, 31, 279-286

[12] J. Qi, Y. Hu, S. Jiang, W. Ma, Z. Yang, Y. Wang, Fuel 2019, 245, 521-527.

[13] D. Oestreich, L. Lautenschütz, U. Arnold, J. Sauer, Chem. Eng. Sci. 2017, 163, 92-104

[14] L. Lautenschütz, D. Oestreich, P. Haltenort, U. Arnold, E. Dinjus, J. Sauer, Fuel Process. Technol. 2017, 165, 27-33.

[15] J. Guilera, E. Ramírez, C. Fité, M. Ibora, J. Tejero, Appl. Catal. A, Gen. 2013, 467, 301-309.

[16] C. J. Baranowski, A. M. Bahmanpour, F. Héroguel, J. S. Luterbacher, O. Kröcher, Catal. Sci. Technol. 2019, 9, 366-376.

[17] H. H. Murray, Appl. Clay Sci. 1991, 5, 379-395.

[18] H. H. Murray, Appl. Clay Sci. 2000, 17, 207-221.

[19] Z. Ding, J. T. Kloprogge, R. L. Frost, J. Porous Mater. 2001, 8, 273293.

[20] A. M. Bahmanpour, F. Héroguel, C. J. Baranowski, J. S. Luterbacher, O. Kröcher, Appl. Catal. A Gen. 2018, 560, 165-170.

[21] F. Uddin, Metall. Mater. Trans. A Phys. Metall. Mater. Sci. 2008, 39 , 2804-2814.

[22] J. T. Kloprogge, J. Porous Mater. 1998, 5, 5-41.

[23] Y. Masui, J. Wang, K. Teramura, T. Kogure, T. Tanaka, M. Onaka, Microporous Mesoporous Mater. 2014, 198, 129-138.

[24] S. Shinde, C. Rode, Catal. Commun. 2017, 88, 77-80.

[25] J. Wang, Y. Masui, K. Watanabe, M. Onaka, Adv. Synth. Catal. 2009, 351, 553-557.

[26] J. Wang, Y. Masui, M. Onaka, Tetrahedron Lett. 2010, 51, 33003303. 
J. Wang, Y. Masui, M. Onaka, European J. Org. Chem. 2010, 17631771.

[28] J. Wang, Y. Masui, M. Onaka, ACS Catal. 2011, 1, 446-454.

[29] J. Wang, J. Ren, X. Liu, J. Xi, Q. Xia, Y. Zu, G. Lu, Y. Wang, Green Chem. 2012, 14, 2506-2512.

[30] J. Wang, Y. Masui, M. Onaka, Appl. Catal. B Environ. 2011, 107, 135-139.

[31] H. Li, J. Ren, L. Zhong, R. Sun, L. Liang, Bioresour. Technol. 2015, 176, 242-248.

[32] T. Hara, M. Hatakeyama, A. Kim, N. Ichikuni, S. Shimazu, Green Chem. 2012, 14, 771-777.

[33] A. Neaman, M. Pelletier, F. Villieras, Appl. Clay Sci. 2003, 22, 153168.

[34] K. Bahranowski, A. Gaweł, A. Klimek, A. Michalik-Zym, B. D. Napruszewska, M. Nattich-Rak, M. Rogowska, E. M. Serwicka, Appl. Clay Sci. 2017, 140, 75-80.

[35] L. Le Forestier, F. Muller, F. Villieras, M. Pelletier, Appl. Clay Sci. 2010, 48, 18-25.

[36] V. K. Soni, R. K. Sharma, ChemCatChem 2016, 8, 1763-1768.

[37] V. K. Soni, P. R. Sharma, G. Choudhary, S. Pandey, R. K. Sharma, ACS Sustain. Chem. Eng. 2017, 5, 5351-5359.

[38] P. J. Wallis, W. P. Gates, A. F. Patti, J. L. Scott, E. Teoh, Green Chem. 2007, 9, 980.

[39] J. Madejová, Vib. Spectrosc. 2003, 31, 1-10.

[40] B. Tyagi, C. D. Chudasama, R. V. Jasra, Spectrochim. Acta - Part A Mol. Biomol. Spectrosc. 2006, 64, 273-278.

[41] L. Yan, C. B. Roth, P. F. Low, J. Colloid Interface Sci. 1996, 184, 663-670.

[42] S. Cadars, R. Guégan, M. N. Garaga, X. Bourrat, L. Le Forestier, F. Fayon, T. V. Huynh, T. Allier, Z. Nour, D. Massiot, Chem. Mater. 2012, 24, 4376-4389.

[43] N. N. Binitha, S. Sugunan, Microporous Mesoporous Mater. 2006, 93, 82-89.

[44] A. Phukan, S. J. Borah, P. Bordoloi, K. Sharma, B. J. Borah, P. P. Sarmah, D. K. Dutta, Adv. Powder Technol. 2017, 28, 1585-1592.
C. Eypert-Blaison, L. J. Michot, B. Humbert, M. Pelletier, F. Villiéras, J. B. D'Espinose de la Caillerie, J. Phys. Chem. B 2002, 106, 730742.

[46] D. Amalric-Popescu, F. Bozon-Verduraz, Catal. Today 2001, 70, 139-154.

[47] R. Alvero, M. D. Alba, M. A. Castro, J. M. Trillo, J. Phys. Chem. 1994, 98, 7848-7853.

[48] W. Jones, Catal. Today 1988, 2, 357-367.

[49] N. J. Clayden, C. M. Dobson, A. Fern, J. Chem. Soc. Dalt. Trans. 1989, 843-847.

[50] S. Indris, M. Scheuermann, S. M. Becker, V. Šepelák, R. Kruk, J. Suffner, F. Gyger, C. Feldmann, A. S. Ulrich, H. Hahn, J. Phys. Chem. C 2011, 115, 6433-6437.

[51] J. Chen, X. P. Wu, L. Shen, Y. Li, D. Wu, W. Ding, X. Q. Gong, M. Lin, L. Peng, Chem. Phys. Lett. 2016, 643, 126-130.

[52] P. Ferrini, J. Dijkmans, R. De Clercq, S. Van de Vyver, M. Dusselier, P. A. Jacobs, B. F. Sels, Coord. Chem. Rev. 2017, 343, 220-255.

[53] C. Fan, Y. Peng, Q. Zhu, L. Lin, R. Wang, A. Xu, J. Phys. Chem. C 2013, 117, 24157-24166.

[54] Y. Yang, Y. Wang, S. Yin, Appl. Surf. Sci. 2017, 420, 399-406.

[55] H. Wang, K. Dou, W. Y. Teoh, Y. Zhan, T. F. Hung, F. Zhang, J. Xu, R. Zhang, A. L. Rogach, Adv. Funct. Mater. 2013, 23, 4847-4853.

[56] T. Barzetti, E. Selli, D. Moscotti, L. Forni, J. Chem. Soc. Faraday Trans. 1996, 92, 1401.

[57] J.-F. Lambert, G. Poncelet, Top. Catal. 1997, 4, 43-56.

[58] S. Ghosh, L. Manna, Chem. Rev. 2018, 118, 7804-7864.

[59] F. Liu, T. Wang, Y. Zheng, J. Wang, J. Catal. 2017, 355, 17-25.

[60] K. Beloufa, N. Sahli, M. Belbachir, J. Appl. Polym. Sci. 2009, 115, 2820-2827.

[61] S. Das, V. Jayaraman, Prog. Mater. Sci. 2014, 66, 112-255.

[62] J. T. Scanlon, D. E. Willis, J. Chromatogr. Sci. 1985, 23, 333-340.

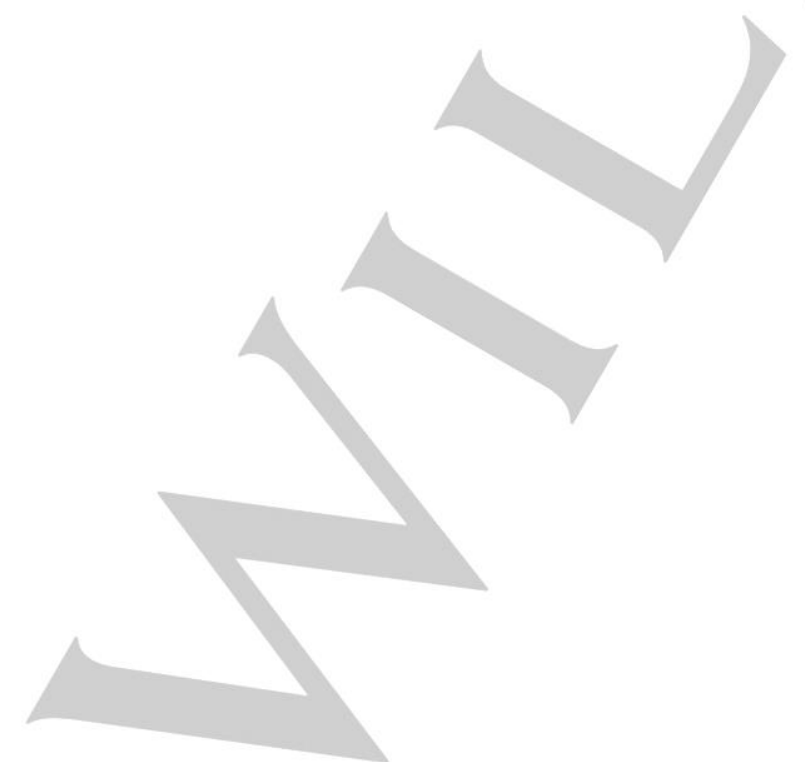


Entry for the Table of Contents (Please choose one layout)

Layout 1:

\section{FULL PAPER}

Cheap and eco-friendly tin montmorillonite clay is an active and stable catalyst for OME synthesis. High activity is attributed to the formation of a hierarchical catalyst with high surface area and accessible Brønsted and Lewis acid sites. Its acidity could be attributed to $\mathrm{Si}-\mathrm{OH}-\mathrm{Al}$ groups and

undercoordinated Sn sites.

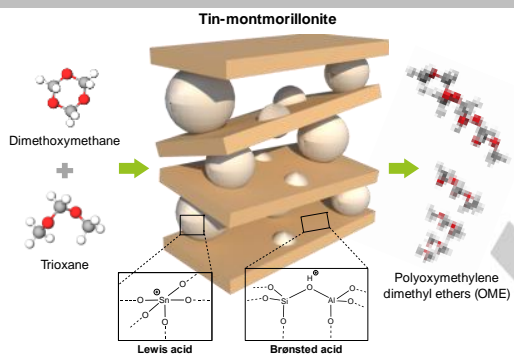

Christophe J. Baranowski, Ali M.

Bahmanpour, Florent Héroguel, Jeremy S. Luterbacher, Oliver Kröcher*

Page No. - Page No.

Insights into the nature of the active sites of tin-montmorillonite for the synthesis of polyoxymethylene dimethyl ethers (OME) 